\title{
FÜZELERDE KULLANILAN KÜÇÜK BİR GAZ TÜRBINNLİ MOTORUN DENEY DÜZENEĞİ, TESTİ VE PERFORMANS ÖLÇÜMÜ
}

\author{
Önder TURAN (ORCID: 0000-0003-0303-4313)* \\ Uçak Gövde-Motor Bakım Bölümü, Havacılık ve Uzay Bilimleri Fakültesi, Anadolu Üniversitesi, Eskişehir, Türkiye
}

Gelis / Received: 22.02 .2017

Düzeltmelerin gelişi / Received in revised form: 18.04 .2017

Kabul / Accepted: 10.05.2017

\begin{abstract}
ÖZ
$\mathrm{Bu}$ çalışmada, deneysel küçük bir turbojet motor test edilerek, motorun performans modellemesi elde edilmiştir. Deneysel turbojet motor, bir havaalı̆̆ı, santrafüj kompresör, ters akışlı yanma odası, eksenel akışlı türbin ve egzozdan oluşmaktadır. Turbojet motor, test hücresinde farklı devirlerde (RPM) test edilerek, itki $(\tau)$, özgül yakıt sarfiyatı (SFC), yakıt debisi (FF) ve egzoz gaz sıcaklığı (EGT) arasındaki değişimler incelenerek matematiksel bağıntılar elde edilmiştir. Turbojet deneyleri, $25.000<\mathrm{RPM}<48.500$ ve $130 \mathrm{~N}<\tau<1.260 \mathrm{~N}$ arasında gerçekleştirilmiştir. Performans parametreleri arasındaki ilişkiler, güvenirlik değerleriyle verilmiştir. Benzer füze tasarımı çalışmalarında enerji sağlayıcı olarak bir turbojet motoru seçilmesi durumunda, bu çalışmanın model olarak alınabileceği öngörülmektedir.
\end{abstract}

Anahtar Kelimeler: Turbojet, itki, bremze, küçük gaz türbini

\section{EXPERIMENTAL SET-UP, TESTING AND PERFORMANCE MODELING OF A TURBOJET ENGINE FOR TARGET DRONE APPLICATIONS}

\begin{abstract}
In this paper, experimental turbojet engine is tested and performed performance modelling of turbojet engine. The main components of this engine include an inlet bell mouth, a centrifugal compressor, a reverse flow combustion chamber, an axial flow turbine and an exhaust. The engine is tested under various shaft speed (RPM) for yielding mathematical correlation between thrust force $(\tau)$, specific fuel consumption (SFC), fuel flow (FF) and exhaust gas temperature. Testing upper and lower limits for shaft speed and thrust are under 25,000< RPM $<48,500$ and $130 \mathrm{~N}<\tau<1,260 \mathrm{~N}$, respectively. Each correlation equations are given with R-squared value. It is expected that this study can be able to a model related to future design work in case of selecting turbojet as an energy supplier of a target drone.
\end{abstract}

Keywords: Turbojet, propulsion, test-cell, small gas turbine

\section{GİRİ̧̧}

II. Dünya savaşına kadar olan süreçte havacılıkta yaygın olarak kullanılan pistonlu motorlar, daha yükse güç ve hızlı manevra ihtiyacı nedeniyle yerini jet motorlarına bırakmak zorunda kalmıştır. O dönemde üretilen 2.000 kW gücündeki bir pistonlu motorun yaklaşık ağırlığı 3.000 kg'1 bulabilmekte ve bu durum hava aracının hareketini ağırlaştırmaktadır. Hava araçlarında, özellikle II. Dünya Savaşında doğan bu ihtiyaç, birim güç başına

*Corresponding author / Sorumlu yazar. Tel.: +90 222335 0580/6945; e-mail / e-posta: onderturan@anadolu.edu.tr 
yüksek güç elde edilebilen turbojet motorlarının doğuşunu ve gelişimini sağlamıştır. Sonraki yıllarda turbojet motorlar uçakların dışında insansız hava araçları (IHA) ve füzelerde yaygın bir şekilde kullanılmaya devam etmiştir.

İHA'lar son yıllarda askeri ve sivil alanda yoğun bir şekilde kullanılmaya başlanmış olup, uçaklarda, helikopterlerde orta-uzun menzil/irtifa/ses hızı parametrelerine göre sinıflandırılmaktadır [1-3].

Turbomakineler, uçaklarda itki sistemi olmaları yanında, küçük boyutlu gaz türbinli türleri gerek füzeler gerekse İHA'lar ve Yedek Güç Ünitelerinin (APU-Auxiliary Power Units) güç üreten ana kaynağını oluşturmaktadırlar. Bunun sebebi ise itki/ağıllık oranlarının bir hayli yüksek olmalarından kaynaklanmaktadır [4]. Bu ölçekteki gaz türbinli motorlarla ilgili pek çok çalışma yapılmış̧ır. Bunlar arasında gerçek gaz hesaplamalarına göre çevrim eniyilemesi yapmıştır $[4,5]$. Yine benzer çalışmalar gaz türbinli motorların enerji ve ekserji analizleri üzerine olmuşstur [6-10].

$\mathrm{Bu}$ çalışmanın amacı, füzelerde kullanılabilecek küçük ölçekli bir gaz türbinli motorun deneysel verileri yardımıyla aşağıdaki parametre çiftlerinin bağıntıları oluşturulmuştur. Deneysel gaz türbinli motor olarak, Anadolu Üniversitesi Havacılık ve Uzay Bilimleri Fakültesi'nde yer alan turbojet motor laboratuarında yer alan TRS18 turbojet motor ele alınmıştır. Anılan motora ait parametre çiftlerinin birbirleriyle olan değişimleri grafiksel olarak bu çalışmada gösterilmiştir. İtki deneylerinde ele alınan parametreler,

a) itki- özgül yakıt sarfiyatı

b) itki-yakıt debisi

c) itki-egzoz gaz sicaklı̆̆

d) yakıt debisi-egzoz gaz sıcaklığı

e) motor devri-özgül yakıt sarfiyatı

f) motor devri-itki kuvveti

g) motor devri-yakıt debisi

h) motor devri-egzoz gaz sıcaklı̆̆ıdır.

Gelișen teknolojiyle paralel olarak gaz türbinli motorlar da her geçen yıl gelişme göstermektedir. Bu gelişim sürecine paralel olarak bu sektörde çalışacak olan bilim insanlarının de her geçen yıl daha donanımlı, daha yüksek bilgi birikimi ve uygulamalı eğitimde ön plana çıkması gerekmektedir. Bu şekilde yapılacak olan gerek araştırmalar gerekse uygulamalı eğitimler, ülkemizin savunma alanına katkıda bulunacağı düş̧ünülmektedir.

\section{MATERYAL VE METOT}

TRS 18 turbojet motorları 1973 yılında geliştirilmiş mikroturbo tip motorlardır. Askeri uygulamalarda, insansız uçaklarda, güdümlü füzelerde ve yardımcı güç ünitelerin de kullanılmak üzere dizayn edilmiş yüksek güvenilirlik ve düşük maliyet özelliği taşıyan turbojet motorlardır [11]. TRS 18 motoru sürekli geliştirilen sistemleriyle günümüzde 160 daN kadar itki üretmektedir. Yüksek itki/ağırlık oranıyla son derece güvenli ve düşük çalışma maliyeti olan bir motordur. Çok sayıda üretilmiş bir motor çeşidi olan TRS 18 turbojet motoru insansız uçaklarda (BD uçaklarında) ve Galileo Avionica tarafından üretilen Mirach 100 tipi güdümlü füzelerde kullanılmaktadır [12]. Şekil 1'de mikrotürbinli motorun bir füze üzerindeki yerleşimi görülmektedir.

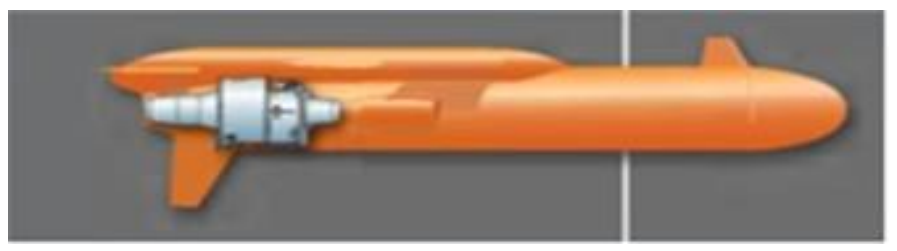

Şekil 1. Mikrotürbinli motorun füze üzerindeki yerleşimi [11]

\subsection{Bir Turbojet Motorun Performans Bağıntıları}

Uçak gaz türbinli motorunun ana bileşenleri hava giriş lülesi, kompresör, yanma odası, türbin ve egzoz lülesidir. Hava giriş lülesinin karakteristiği, akışın sesaltı ve sesüstü olmasına göre değişir. Her iki durumda da hava giriş lülesinin görevi; kompresör ya da fana yüksek durgunluk basıncında, en az seviyede sıcaklık ve basınç değişimi sağlayacak şekilde hava emişini sağlamaktır.

Uçak gaz türbinli motorlarda eksenel ve merkezcil akımlı olmak üzere iki tip kompresör kullanılmaktadır. Merkezcil kompresörlerde akış, eksene yakın ve merkezden dış yarıçapa doğrudur. Bu tip kompresörlerin avantajı birim kademe başına daha fazla sıkıştırma oranına sahip olmasıdır. Dezavantajı büyük ön alana sahip 
olması ve veriminin düşük olmasıdır. Kullanımda küçük motorlarda ya da büyük motorlarda son kademe olarak kullanılırlar.

Yakıtın püskürtüldüğü, buharlaştığı ve yanmanın olduğu motor bileşeni ise yanma odasıdır. Zengin karışım, yanma odası hattından gelen soğuk havayla karışır. İyi bir yanma odası tasarımı en düşük basınç kaybıyla yakıtın tam yanmasını sağlayacak şekilde olmalıdır.

Uçak gaz türbinli motorlarda kullanılan türbinler eksenel akışlı türbinlerdir ve eksenel akışlı kompresörlerle beraber kullanılırlar. Türbine giren gaz çok yüksek sıcaklıktadır ve ilk türbin kademesi kompresörden gelen soğutma havasıyla soğutulmalıdır. Türbin soğutması beraberinde motor performansında azalma meydana getirdiğinden yüksek sıcaklığa dayanıklı malzeme kullanılarak yüksek türbin giriş sıcaklığı elde edilmelidir.

Uçak gaz türbinli motorun son bileşeni egzoz lülesidir ve bu bileşende yüksek basınçlı egzoz gazlarını atmosfere atılmasını sağlanır. Farklı Mach sayılarında lüle çıkış basınç oranı da farklılık gösterir. Optimum lüle performansı, lüle çıkış basıncının atmosfer basıncına yakın bir değerde olmasıyla gerçekleşir.

Hava emişli motorlarda en çok kullanılan iki parametre, Eşitlik 1'de gösterilen özgül itki kuvveti (itki kuvvetinin motordan geçen toplam hava debisine oranı) ve Eşitlik 2'de verilen özgül yakıt sarfiyatıdır.

$$
\begin{aligned}
& \text { Özgül itki }=\frac{\text { Kuvvet }}{\text { Hava debisi }}(N . s / \mathrm{kg}) \\
& \text { Özgül yakıt sarfiyatı }=\frac{\text { Yakıt debisi }}{\text { Kuvvet }}(g / k N . s)
\end{aligned}
$$

Bu iki parametre, 1sıl ve itki verimleriyle doğrudan ilişkilidir. Motordan elde edilen faydalı mekanik güç, egzoz lülesindeki kinetik enerjinin bir oranıdır. Aynı zamanda bu kinetik enerji, bir motor tasarımcısı için elde edeceği itki kuvvetidir. Yerel bir gaz türbinli motor için egzoz akımının kinetik enerjisi ilave bir türbin kademesiyle şaft gücüne çevrilir. Bu ilave bileşenlerin eklenmesiyle uçak motoruna göre, yerel gaz türbinli motorun 1sıl veriminin düşük olması ve bileşen verimlerinde daha fazla kayıp meydana gelmesi gibi sonuçlar doğurur. İtki verimi, motorun ürettiği enerjinin uçuş aracına ilettiği faydalı güce oranıdır. İtki verimi, Eş.(3)'de verildiği gibi, itki kuvvetinin motorun ürettiği güce oranı olarak ifade edilmektedir.

$$
\text { İtki verimi }=\frac{\text { İtki kuvveti } \mathrm{x} \text { Uçu ş hız }}{\text { Motordan elde edilen güç }}
$$

Isıl verim ise motora giren enerjinin motordan elde edilen güce oranıdır.

$$
\text { Isıl verim }=\frac{\text { Motordan elde edilen güç }}{\text { Yanma odasına giren güç }}
$$

Toplam (overall) verim ise, itki ve ısıl verimlerinin çarpımına eşittir ve motor verimi ifade edilirken toplam verim esas alınmaktadır.

$$
\text { Toplam verim }=\text { İtki verimi } \mathrm{x} \text { Isll verim }
$$

Turbojet motorlara ait çevrim analizleriyle ilgili eşitlikleri çeşitli kaynaklarda bulmak mümkündür [13-15]. Bu eşitlikler yardımıyla gerek teorik gerek deneysel amaçlı motorlara ait ölçülmeyen ve bilinmesi gereken motor istasyonlarına ait basınç, sıcaklık gibi değerleri bulmak mümkündür.

\subsection{Deneysel Motorun Yapısı, Teknik Özellikleri ve Test Düzeneği}

Araştırmaya konu olan turbojet motoru (TRS 18) tek şaftlı (gaz türbinli) küçük ölçekli gaz türbinli bir motor olup tek kademe eksenel bir türbine sahiptir. Motorun temel özellikleri Tablo 1'de, deney odasındaki görünümü Şekil 2'de, motorun ana elemanları Şekil 3'te gösterilmektedir.

Tablo 1. Motora ait genel özellikler

\begin{tabular}{|c|c|c|c|c|c|}
\hline $\begin{array}{c}\text { Maksimum } \\
\text { Devir }\end{array}$ & $\begin{array}{c}\text { Maksimum } \\
\text { Uçak, Füze Hızı }\end{array}$ & $\begin{array}{c}\text { Özgül Yakıt } \\
\text { Sarfiyatı }\end{array}$ & $\begin{array}{c}\text { Elektrik Güç } \\
\text { Sarfiyatı }\end{array}$ & $\begin{array}{c}\text { Jeneratör } \\
\text { Akımı }\end{array}$ & $\begin{array}{c}\text { Motor } \\
\text { Ăğırlığı }\end{array}$ \\
\hline $48.250 \mathrm{RPM}$ & $0,9 \mathrm{M}$ & $1,20 \mathrm{~kg} /(\mathrm{daN} . \mathrm{h})$ & $1,5 \mathrm{~kW}$ & $53 \mathrm{~A}$ & $42 \mathrm{~kg}$ \\
\hline
\end{tabular}


Ö. TURAN

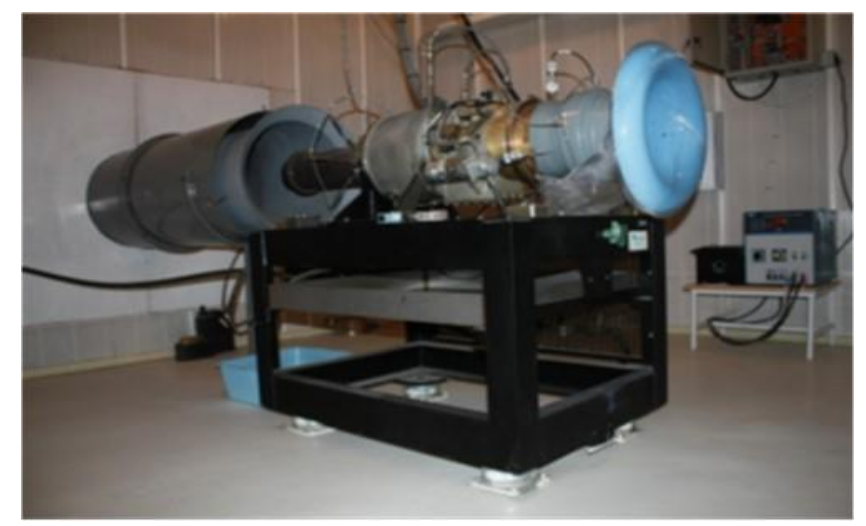

Şekil 2. Turbojet motorun test odasındaki görünümü

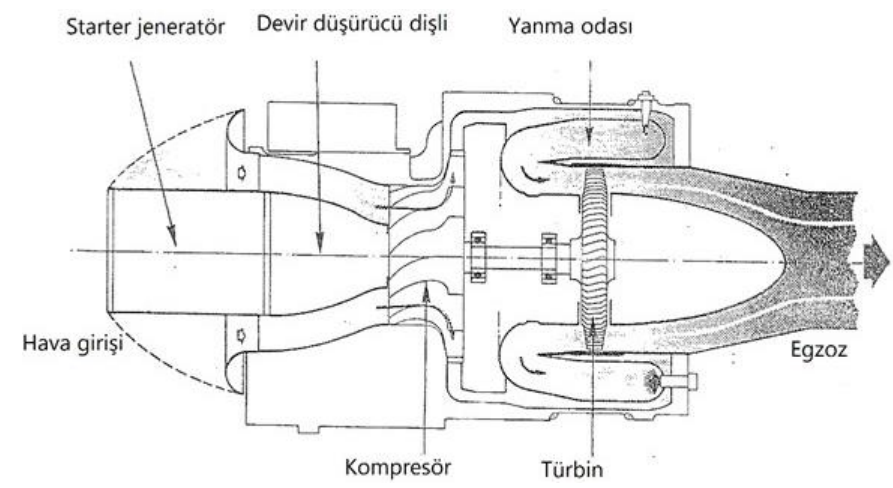

Şekil 3. Turbojet motorunun ana elemanları

Deneysel turbojet motorunun yağlama sistemine ait motor bloğunun altında bulunan bir yağ deposu bulunmaktadır. Kompresörden tahliye edilen basınçlı hava ile çalışan (P2) yağ pompası yağ deposunun içindedir. Yağ pompası yağ deposundan aldığı yağı kalın gözenekli yă̆ filtresinden geçirir ve motor yataklarının yağlanması için gerekli basıncı sağlar. Yataklardan gelerek geri dönüş hattında bulunan yağ devir düşürücü dişlileri yağlamak için kullanılır. Yağ içerisindeki istenmeyen hava santrifüj hava aratıcı tarafından yağdan alınarak atmosfere atılır. Turbojet motorun yağlama hattı Şekil 4’te gösterilmiştir.

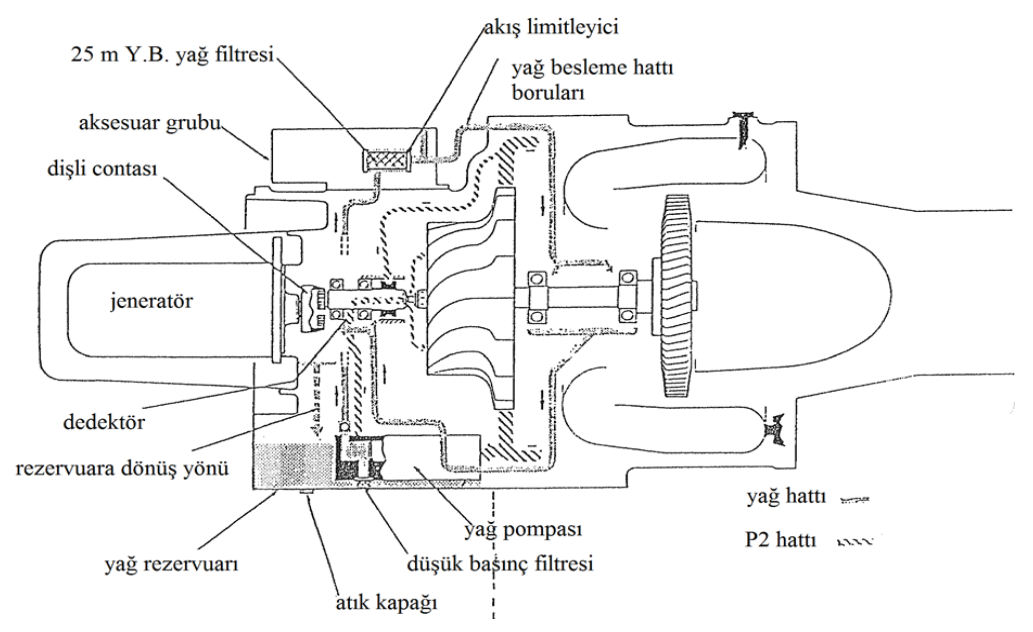

Şekil 4. Turbojet motorunun yağlama sistemi elemanları

Termokoupl tipte olan egzoz gaz sıcaklığı (EGT) sensörü egzoz lülesine özel bir kaynak tekniği ile yerleştirilmiştir. $\mathrm{Bu}$ tip sensörlerin içerisinde sıcaklıkla direnci değişen bir eleman bulunmakta olup sıcaklık 
bilgisi elektriksel sinyale çevrilmekte ve egzoz gaz sıcaklığı ölçülmektedir. EGT sensörü Şekil 5'te gösterilmiştir.

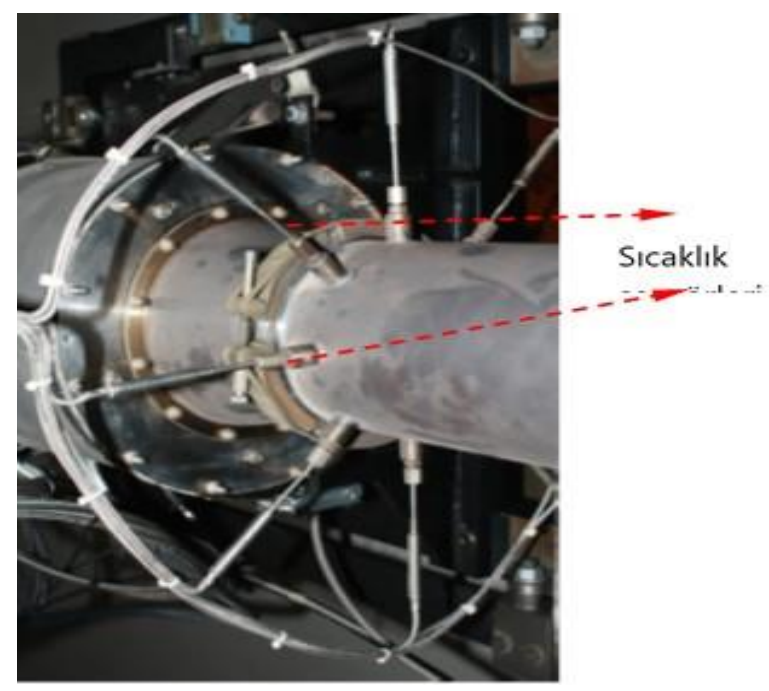

Şekil 5. Turbojet motorunun egzoz sıcaklık sensörleri

Şekil 6'da ise deneysel motorun yakıt sistemi gösterilmektedir. Yakıt sisteminde yakıt pompası, aksesuar grubu, 25 mikron yüksek basınç (HP) filtresi, 40 mikron spill yakıt filtresi, tek yönlü valf, PC1 (yanma odasına giden yakıt basınc1) test noktası, PC2 (yanma odası fazla tahliye yakıtın basınc1) test noktası, yakıt bloğu, on püskürtme delikli yakıt brülörü, kaplama ve yakıt manifoldu boşaltma valfi ve yakıt borusu hattı yer almaktadır. Kontrol kutusu yanma odasından ve sıcaklık sensöründen sinyal almakta, bu bilgi fonksiyonların doğruluğunu denetlemede ve gaz (throttle) potansiyometresinin kurulmasında kullanılmaktadır. Kontrol sinyali yakıt kontrol valfine gönderilir ve yakıt akışı düzenlenir. Turbojet motorun ilk dönü hareketi elektriksel olarak veya hava ile starterin döndürülmesiyle elde edilebilmektedir. Elektriksel çalışma sistemi; starter jeneratör, ters akım bağlantı frenleyicisi ve voltaj regülatöründen oluşur.

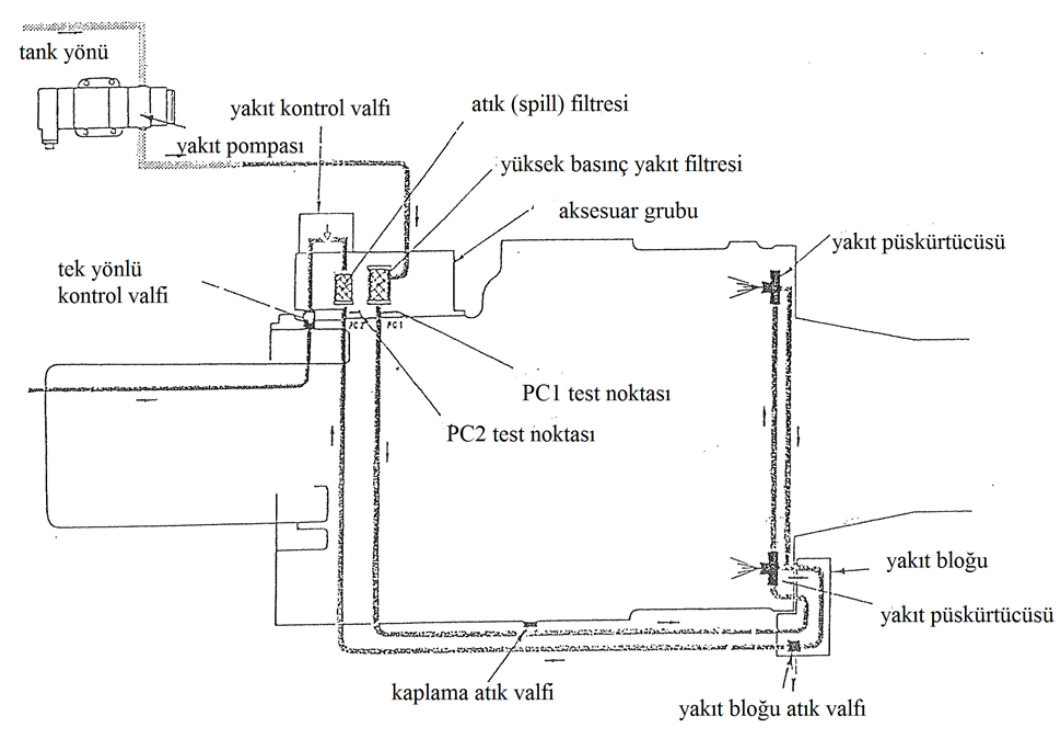

Şekil 6. Turbojet motorun yakıt sistemi

Motor çalıştırma düğmesine basıldıktan sonra elektronik kontrol ünitesinden gelen güç, ters akım bağlantı frenleyicisi ile voltaj regülatörüne, türbini çeviren starter jeneratörüne ve rotoru çeviren dişli kutularına iletilir. Turbojet motorların çalışma esası Brayton çevrimidir. Bir itki sisteminin Brayton çevriminin oluşturulması için temel büyüklükler bilinmelidir. Bilindiği gibi gazların basınç, sıcaklık ve hacim gibi özellikleri vardır. Bu değişken özellikler çalışma esnasında birbiri ile olan etkileşimleri sonucu belirli değerler arasında değişkenlik 
göstererek tekrar aynı özelliklerine geri dönerler. Bu dönüşüm sürecine çevrim denilmektedir. İşte bir güç grubuna ait bir çevrimin oluşturulmasıyla motorun termodinamik haritasını da ortaya çıkartacaktır. Şekil 7'de deneysel turbojet motorunun parametre ölçüm istasyonları, Şekil 8'de ise bir turbojet motoruna ait çevrim T-s diyagramı gösterilmektedir. Tablo 2 'de ise ölçülen parametrelerin açıklamaları verilmiştir. Şekil 7'de deneysel turbojet moturunun iç hava akışı, içyapısı, ana bileşenleri ve motor üzerinden ölçülen ve hesaplanan motor parametreleri görülmektedir. İstasyon numaralarına göre deneysel turbojet motoru şu bölümlerden oluşmaktadır:

- 0-2 arası: Bellmouth, starter jeneratör ve devir düşürücü

- 2-3 arası: Radyal akışlı kompresör

- 3-4 arası: Ters akışlı annular tip yanma odası

- 4-5 arası: Eksenel akışlı türbin

- 5-9 aras1: Egzoz bölümü

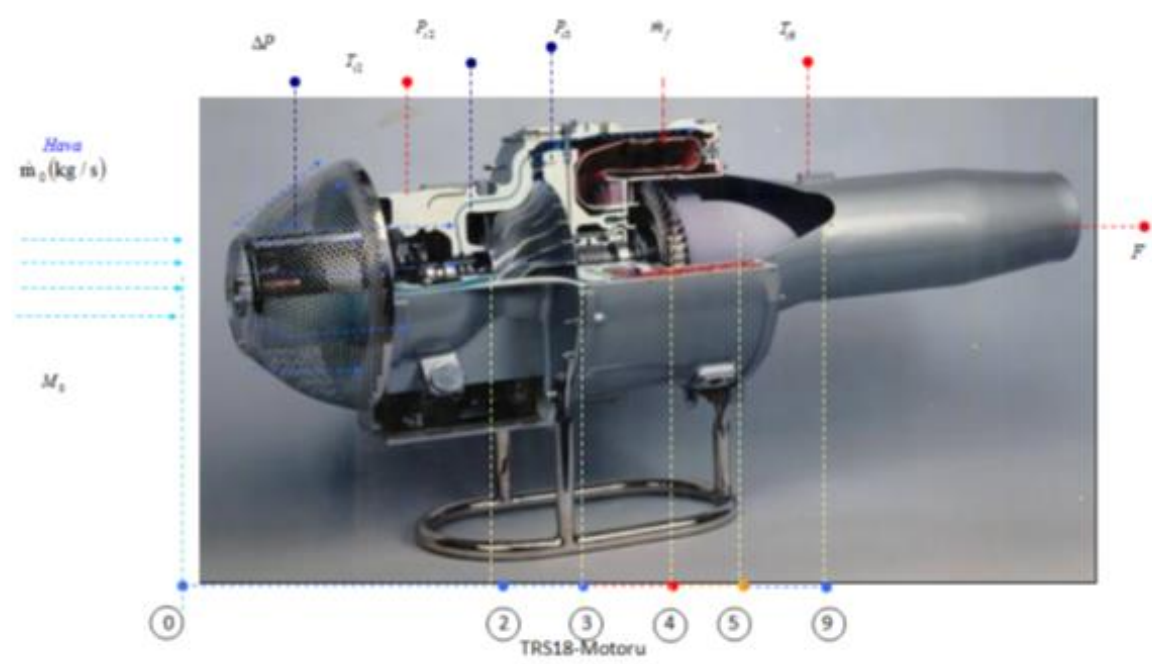

Şekil 7. Turbojet motorunun performans ölçüm sensörlerinin motor üzerindeki yerleşimi

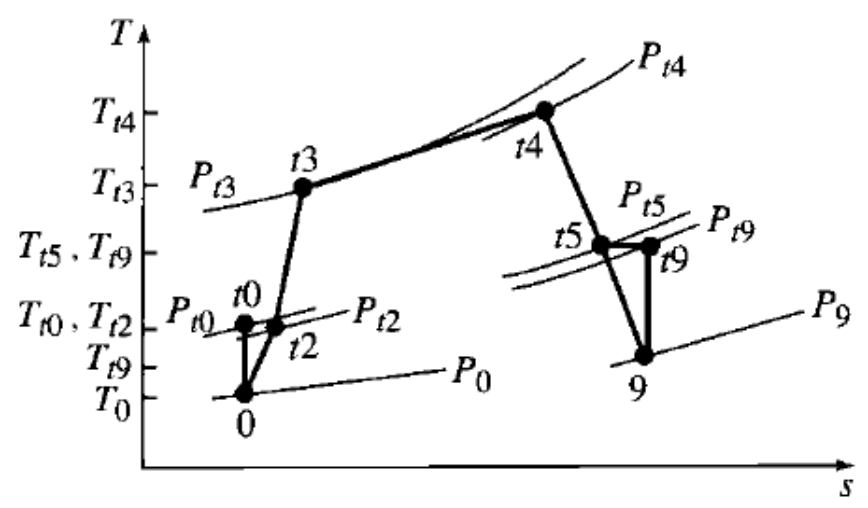

Şekil 8. Bir turbojet motoruna ait genel T-s diagramı

Şekil 9'da deneysel turbojet motorunun kontrol konsolu görülmektedir. Test odasında, yakıt yönetim paneli, motor sehpası, elektrik güç ünitesi ve aksesuarlar bulunmaktadır. Bu konsol üzerinde;

- Motor devri göstergeleri (hem analog hem de dijital)

- Kompresör giriş sicaklığ 1

- ECU (Engine Control Unit) kontrol anahtarı

- Potansiyometre (Motor devir ayarlayıc1)

- Motor buji test düğmesi

- Start düğmesi bulunmaktadır.

Merkez konsolun sol tarafında kalan kabinde ise aşağıdaki önemli motor parametreleri ilgili parantez içinde belirtilen ölçüm cihazları yardımıyla parametreler ölçülebilmektedir; 
- Motor itki kuvveti (Load cell)

- Yakıt debisi (Akışmetre)

- Motor titreşim değeri (Titreşim pick-up)

- Egzoz gaz sıcaklıkları (8 adet sıcaklık sensörü)

- Yağ ve yakıt sıcaklıkları (Transmitter)

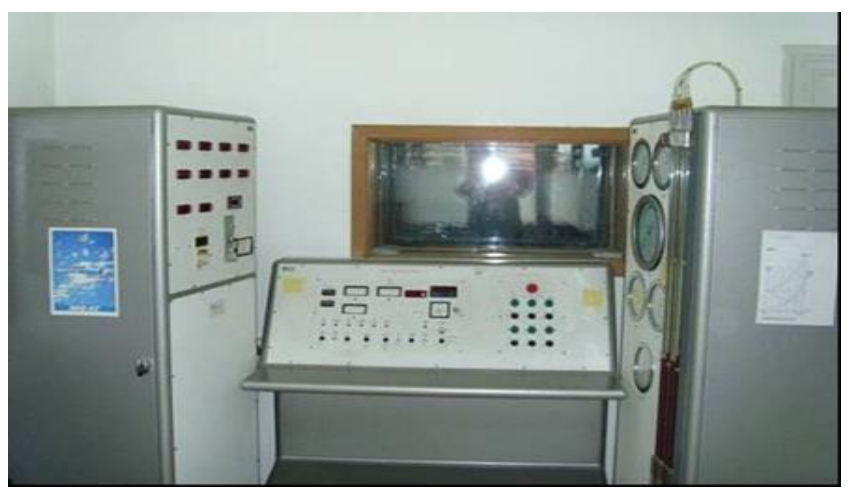

Şekil 9. Deneysel turbojet motorunun kontrol odası merkez konsolu

Şekil 10'da görülen basınç göstergelerinde ise bellmouth fark basıncı, kompresör giriş ve çıkış basıncı ve yağlama yağının basınç değerleri ölçülebilmektedir.

Şekil 2'de test odasındaki resmi görülen deneysel turbojet motoru çalıştırılırken, öncelikle rölanti hızında 3 dakika çalıştırıldıktan sonra motor kapatılmakta ve motorda kaçak olup olmadığ kontrol edilir.

Maksimum güçte çalıştırılırken ise motor 5 dakika çalıştırlıp kapatıldıktan sonra kaçak kontrolü ve yağ seviyesi kontrol edilip, motor konsolundaki tüm anahtarlar ilk konumlarına getirilir.

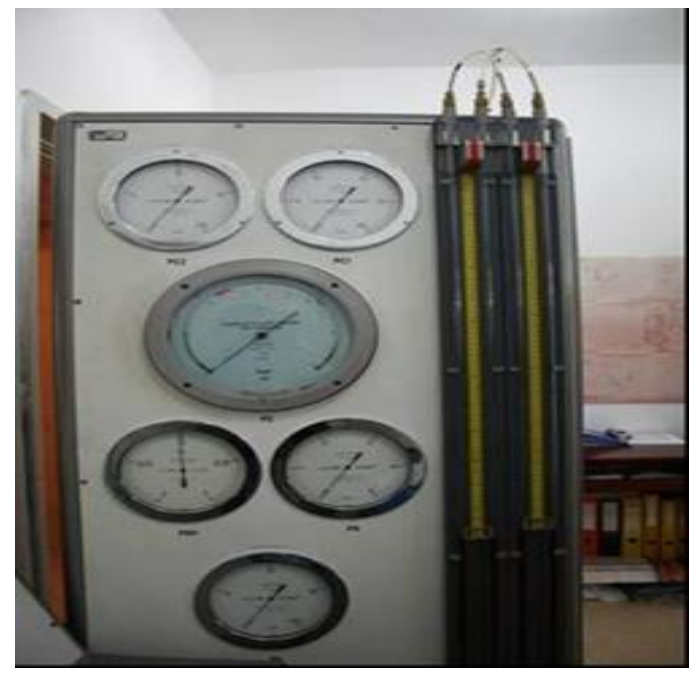

Şekil 10. Deneysel turbojet motorunun test odasındaki basınç göstergeleri

Deneysel amaçlı turbojet motorunun test edilmesi ve testten elde edilen motor parametrelerinin değerlendirilmesi, motorun performansı ortaya çıkarılması bakımından önem taşımaktadır. Motor bremzesinden elde edilen performans parametrelerini doğrudan ölçülebilen ve formüller yardımıyla hesaplanan parametreler olarak iki bölüme ayırmak mümkündür. Bunlardan biri olan motor hava debisi $\left(\dot{m}_{0}\right)$ iki yöntemle bulunur. Bunlardan biri motor bremze el kitapçı̆̆ında verilen [17];

$$
\dot{m}_{0}(\mathrm{~kg} / \mathrm{s})=K\left(1-A \frac{\Delta P}{P_{t 2}}\right)\left(\sqrt{\frac{\Delta P P_{t 2}}{T_{t 2}}}\right)
$$


$\mathrm{K}=0,271597$ ve $\mathrm{A}=0,413646$ değerlerinde birer deneysel sabit katsayı olup, Eşitlik (6)'da $T_{t}$ sıcaklığı Kelvin, $P$ basınç değerleri de mbar biriminde alınarak Eşitlik (6)'da kullanılmaktadır. Eşitlik (6)'da verilen ifade, yapımcı firma tarafından el kitapçı̆̆ında verilen bir ifade olup, bu formülde $P_{t 2}$ mbar cinsinden kompresöre giren havanın toplam basınc1, $T_{t 2}$ Kelvin biriminde olmak üzere kompresöre giren havacının toplam sıcaklığ1, $\Delta P$ ise havaalığı girişindeki toplam ve statik basınç farkının mbar cinsinden ifadesidir. Hava giriş debisini bulmak için kullanılacak bir diğer eşitlik ise süreklilik formülüdür. Buna göre;

$$
\dot{m}_{0}(\mathrm{~kg} / \mathrm{s})=\rho_{\text {hava }} V_{0} A
$$

Eşitlik (7)'de $V$, havanın motora giriş hızı, $A$ havaalığı (bellmouth) alanı, $\rho_{\text {hava }}$ ise havanın yoğunluğudur. $V_{0}$ hızının bulunması için bellmouth giriş fark basıncının $(\Delta P)$ bilinmesi gerekmektedir. Bu değer manometreden okunan renklendirilmişs suyun yükseklik değeri okunarak;

$$
\Delta P=\rho_{s u} g h
$$

eşitliği yardımıyla bulunur. Eşitlik (8)'de $\rho_{s u}$ suyun yoğunluğu, $g$ yerçekimi ivmesi, $h$ ise suyun yüksekliğidir. Motor giriş hava hızının bulunması için;

$$
\Delta P=\frac{1}{2} \rho_{\text {hava }} V_{0}^{2}
$$

eşitliği kullanılmaktadır.

Deneysel turbojet motorunun itki kuvveti $(F)$, motor sehpası üzerine yerleştirilmiş load-cell vasıtasıyla ölçülmektedir. Motorda kullanılan yakıt Jet-A1 yakıtı olup, kimyasal formülü tam olarak yazılamasa da $C_{12} H_{23}$ olarak kabul edilebilir [16]. Bu yakıtın alt ısıl değeri yaklaşık olarak $43.000 \mathrm{~kJ} / \mathrm{kg}$ 'dır. Motorun yanma odasına giden yakıtın debisi motor test odasına yerleştirilmiş bir akışmetre vasıtasıyla ölçülmektedir. Ölçülen değer hacimsel debidir $(\dot{V})$ ve kütlesel debiye çevirmek $\left(\dot{m}_{f}\right)$ için;

$$
\dot{m}_{f}(\mathrm{~kg} / \mathrm{s})=\rho_{y a k t} \dot{V}
$$

eşitliği kullanılır. Burada $\rho_{\text {yakt }}$ yakıtın yoğunluğudur.

Tablo 2. Ölçülen parametreler

\begin{tabular}{|c|c|}
\hline Deney no & Açıklama \\
\hline$\Delta \mathrm{P}\left(\mathrm{mmH}_{2} \mathrm{O}\right)$ & Bellmouth fark basıncı \\
\hline $\mathrm{P}_{\mathrm{t} 2}\left(\mathrm{mmH}_{2} 0\right)$ & Kompresör giriş toplam basıncı \\
\hline $\mathrm{P}_{\mathrm{t} 3}(\mathrm{bar})$ & Kompresör çıkış toplam basınc1 \\
\hline$\dot{m}_{f}(l t / h)$ & Yakıt debisi \\
\hline $\mathrm{T}_{\mathrm{t} 9}\left({ }^{0} \mathrm{C}\right)$ & Egzoz çıkış toplam sıcaklı̆̆ 1 \\
\hline $\mathrm{T}_{\mathrm{t} 2}\left({ }^{0} \mathrm{C}\right)$ & Kompresör giriş toplam sıcaklı̆̆ 1 \\
\hline$\tau(\mathrm{N})$ & Motor İtkisi \\
\hline$\dot{\mathrm{m}}_{0}(\mathrm{~kg} / \mathrm{s})$ & Hava debisi \\
\hline
\end{tabular}

Gerek hesaplamalarla gerek motor testi esnasında kaydedilen ölçümlerle hava ve yakıt debilerinin elde edilmesinin ardından yakıt-hava oranı $(f)$ ve hava-yakıt oranı (1/f), Eşitlik (11) ve (12) yardımıyla bulunmaktadır.

$$
\text { Yakıt - hava oranı }(f)=\frac{\dot{m}_{f}}{\dot{m}_{0}}
$$




$$
\text { Hava - yakıt oranı }(1 / f)=\frac{\dot{m}_{0}}{\dot{m}_{f}}
$$

Motora giren akışkan hava ve yakıt akışkan miktarları bulunduktan sonra uçak gaz türbinleri çok önemli olan iki performans parametresi olan özgül yakıt sarfiyatı (SFC-specific fuel consumption) ve özgül itki (ST-specific thrust) sırasıyla Eşitlik (13) ve (14) yardımıyla aşağıdaki gibi ifade edilmektedir:

$$
\begin{aligned}
& \text { Özgül yakıt sarfiyatı }(S F C)=\frac{\dot{m}_{f}}{F} \\
& \text { Özgül itki }(S T)=\frac{F}{\dot{m}_{0}}
\end{aligned}
$$

\section{BULGULAR VE TARTIŞMA}

Tablo 3'te deneysel turbojet motorunun test edilmesinden sonra ölçülen ve hesaplanan motor performans değerleri verilmiştir. Şekil 11-18'de ise deneysel verilerle elde edilen turbojet motora ait performans eğrileri ve motor davranışı görülmektedir.

Tablo 3. Deneysel turbojet motorunun maksimum devirdeki performans değerleri

\begin{tabular}{|l|c|c|}
\hline \multicolumn{1}{|c|}{ Açıklamalar } & Simge (Birim) & Değer \\
\hline Motor devri (RPM) & $N($ devir/dk) & 48500 \\
\hline Bellmouth fark basıncı & $\Delta P(\mathrm{kPa})$ & 2045 \\
\hline Kompresör giriş toplam basıncı & $P_{t 2}(\mathrm{kPa})$ & 101 \\
\hline Kompresör çıkış toplam basıncı & $P_{t 3}(\mathrm{kPa})$ & 333 \\
\hline Kompresör sıkş̧tırma oranı & $\pi_{c}$ & 3,28 \\
\hline Yakıt debisi & $\dot{m}_{f}(\mathrm{lt} / \mathrm{h})$ & 208 \\
\hline Yakıt debisi & $\dot{m}_{f}(\mathrm{~kg} / \mathrm{s})$ & 0,045 \\
\hline Hava debisi & $\dot{m}_{0}(\mathrm{~kg} / \mathrm{s})$ & 2,27 \\
\hline Yakıt-hava oranı & $f$ & 0,02037 \\
\hline Hava-yakıt oranı & $1 / f$ & 49,09 \\
\hline Egzoz çıkış toplam sıcaklığ1 & $T_{t 9}\left({ }^{\circ} \mathrm{C}\right)$ & 810 \\
\hline Kompresör giriş toplam sıcaklığ 1 & $T_{t 2}\left({ }^{\circ} \mathrm{C}\right)$ & 10,1 \\
\hline Motor itkisi & $\tau(\mathrm{N})$ & 1286 \\
\hline Özgül yakit sarfiyatı & $S F C\left[\mathrm{~g} .(\mathrm{kN} . \mathrm{s}){ }^{-1}\right]$ & 36,2 \\
\hline
\end{tabular}

Şekil 11'de itki kuvvetiyle özgül yakıt sarfiyatı değişimi görülmektedir. 130-1260 N kuvvet aralığında özgül yakıt sarfiyatının azaldığı görülmüştür. Yüksek itki kuvvetinin elde edildiği değerlerde özgül yakıt sarfiyatındaki azalma ivmesinin yavaşladığı ve bir noktadan sonra sabit kaldığı gözlemlenmiştir.

Şekil 12'de itki kuvvetiyle yakıt debisi arasındaki ilişki görülmektedir. 130 N'luk bir itki kuvveti elde etmek için gereken yakıt debisi $27.16 \mathrm{~kg} / \mathrm{h}$ iken maksimum itki değeri olan $1260 \mathrm{~N}$ değerinde $149.27 \mathrm{~kg} / \mathrm{h}$ 'lik bir yakıt debisi akışı görülmektedir. Yüksek itki kuvveti için gerekli yakıt debisi artış ivmesi yüksek değerlerde hızlı bir artış göstermektedir.

Şekil 13'de turbojet motorunun itki kuvvetiyle egzoz gaz sıcaklığı arasındaki ilişki gösterilmektedir. 130-1260 N'luk itki kuvvet aralığında egzoz gaz sıcaklığının $705^{\circ} \mathrm{C}-1015^{\circ} \mathrm{C}$ arasında değiştiği görülmektedir. Düşük devirlerde yani düşük itki kuvvetinin olduğu noktalarda egzoz gaz sıcaklığında değişim görülmemekte ancak özellikle 700 N'luk itki seviyesinin üzerindeki değerlerde egzoz sıcaklığını belirgin bir biçimde arttı̆̆ görülmüştür.

Yakıt debisinin artmasıyla itkinin arttığı Şekil 12'de, itki-egzoz gaz sıcaklığı arasındaki ilişki de Şekil 13'de gösterilmişti. Şekil 14'de ise yakıt debisiyle egzoz gaz sıcaklığı arasındaki ilişki görülmektedir. Tıpkı itkide olduğu gibi yakıt debisinin düşük miktarlarındaki $(20-80 \mathrm{~kg} / \mathrm{h})$ değerlerinde egzoz gaz sıcaklığı değişimi düşük iken, özellikle 90-150 kg/h değerlerine ulaşıldığında egzoz gaz sıcaklığı belirgin bir şekilde arttığı gözlenmiştir. 


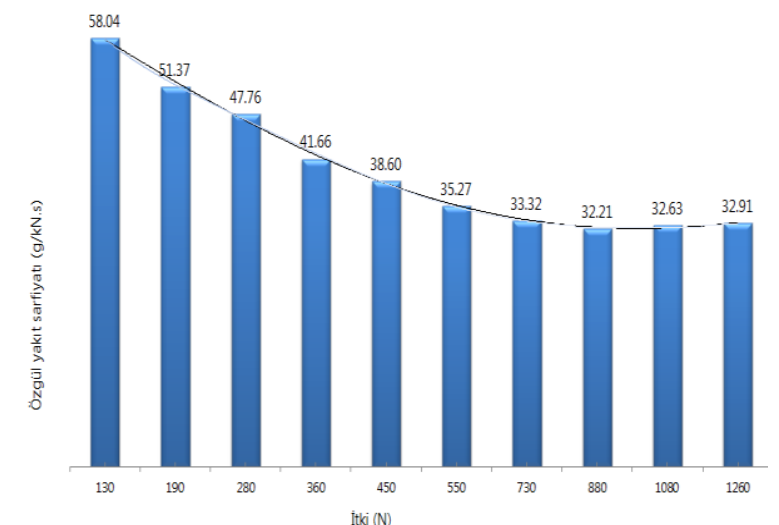

Şekil 11. Deneysel motorun itki kuvvetiyle özgül yakıt sarfiyatının değişimi

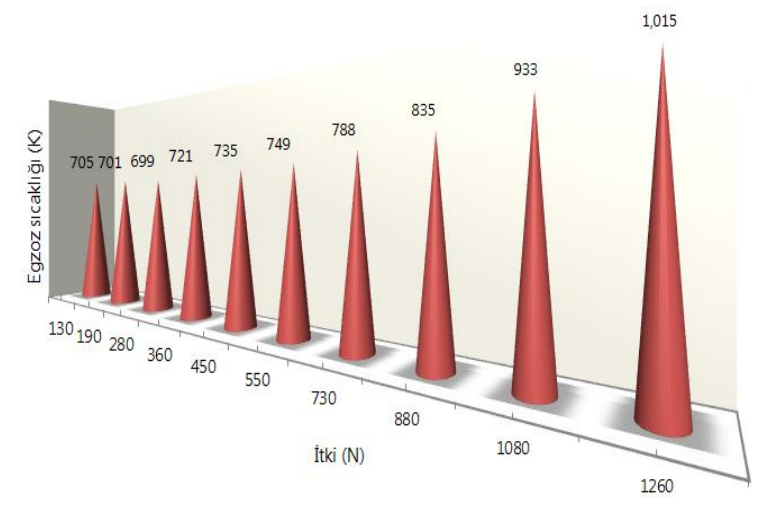

Şekil 13. Deneysel motorun itki kuvvetiyle egzoz sıcaklığının değişimi

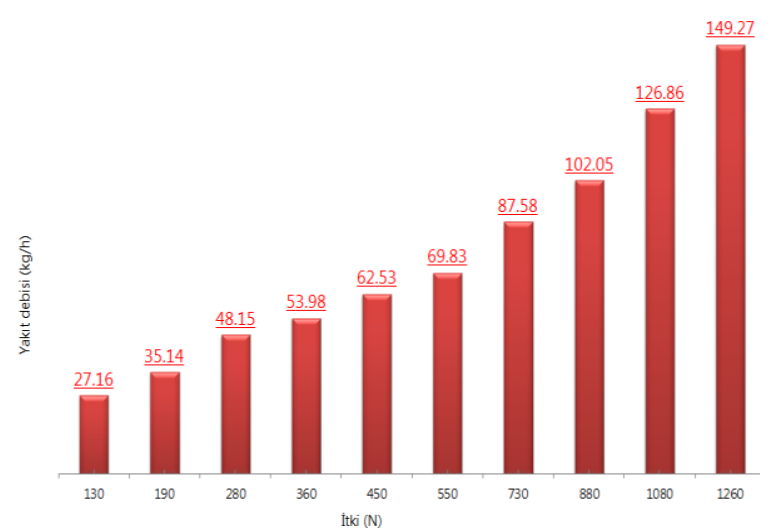

Şekil 12. Deneysel motorun itki kuvvetiyle yakıt debisinin değişimi

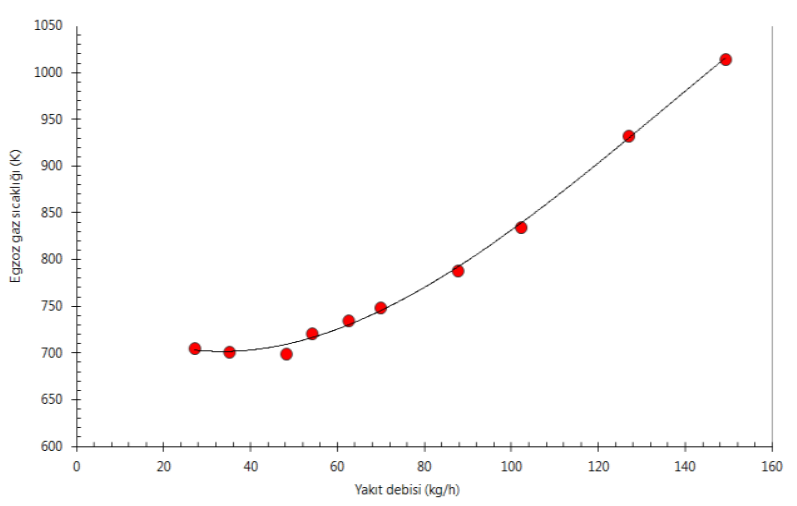

Şekil 14. Deneysel motorun yakıt debisiyle egzoz gaz sıcaklığının değişimi

Şekil 15'de kompresör ve türbini bağlayan şaftın dönüş devri (motor devri veya şaft hızı) ile özgül yakıt sarfiyatının değişimi görülmektedir. Motor devri arttıkça daha fazla itki kuvveti, daha verimli yanma sayesinde motor verimi artacak motorun özgül yakıt sarfiyatı ise azalacaktır. Yüksek devirlere çıkıldığında ise değişim neredeyse sabit kalmakta ve özgül yakıt sarfiyatı 42.000-48.000 devir aralığında $34 \mathrm{~g} / \mathrm{kN} \cdot \mathrm{s}$ değerinde sabit kalmaktadır.

Şekil 16'da motor devir ile itki kuvveti arasındaki değişim görülmektedir. Motor devri itki üzerinde neredeyse doğrusal bir artış davranışı göstermektedir. Rölanti devri olan 25.000 RPM'de itki kuvveti 160 N iken, 48.000 RPM'de $1200 \mathrm{~N}$ değerine ulaşmaktadır.

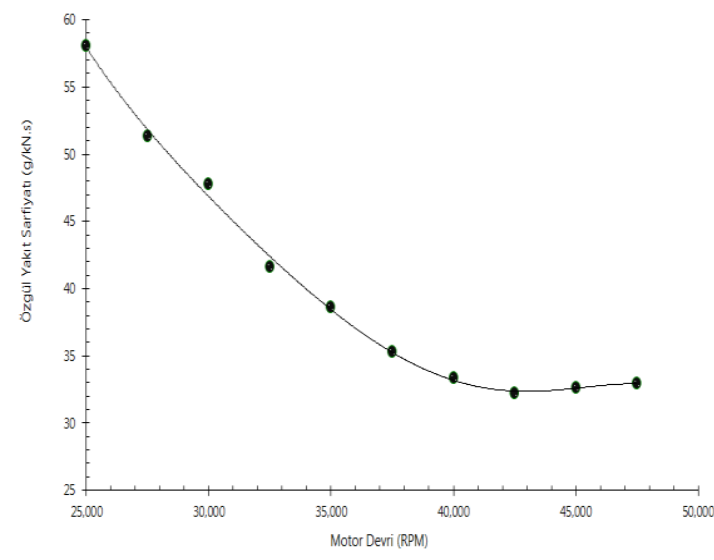

Şekil 15. Deneysel motorun motor devriyle özgül yakıt sarfiyatıyla değişimi

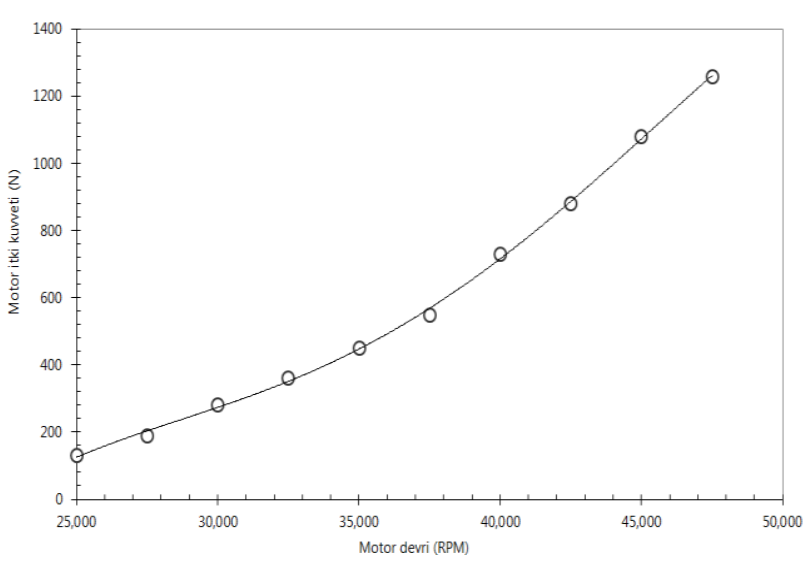

Şekil 16. Deneysel motorun motor devriyle itki kuvvetinin değişimi 
Şekil 17'de ise motor devri ile motorun yanma odasına giden yakıt debisi arasındaki ilişki görülmektedir. Motor devrinin artması için motora daha fazla yakıt debisinin gönderilmesi gerekmekte olup, aradaki matematiksel ilişskinin ifadesi için Şekil 17'ye başvurmak gerekir. Bu şekle göre iki değişken arasındaki ilişki özellikle yüksek devirlerde doğrusal bir fonksiyon olacak şekilde olduğu görülmektedir.

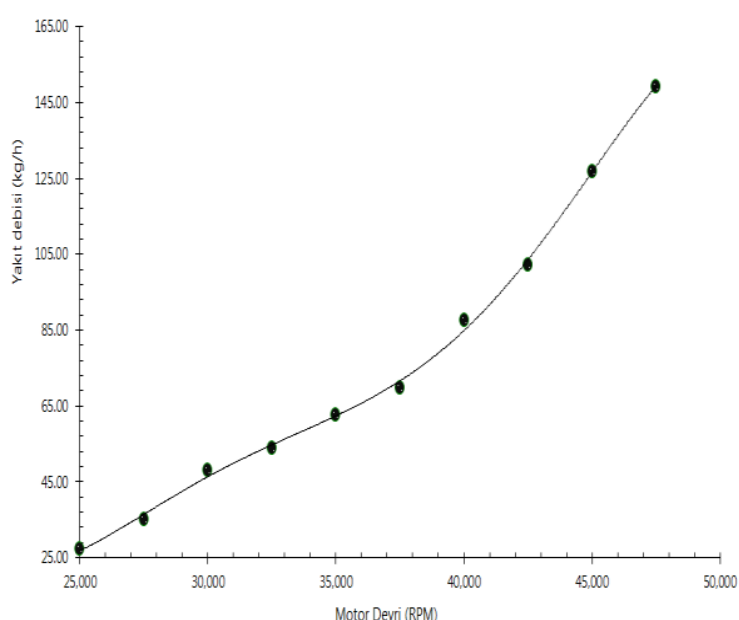

Şekil 17. Deneysel motorun motor devriyle yakıt debisinin değişimi

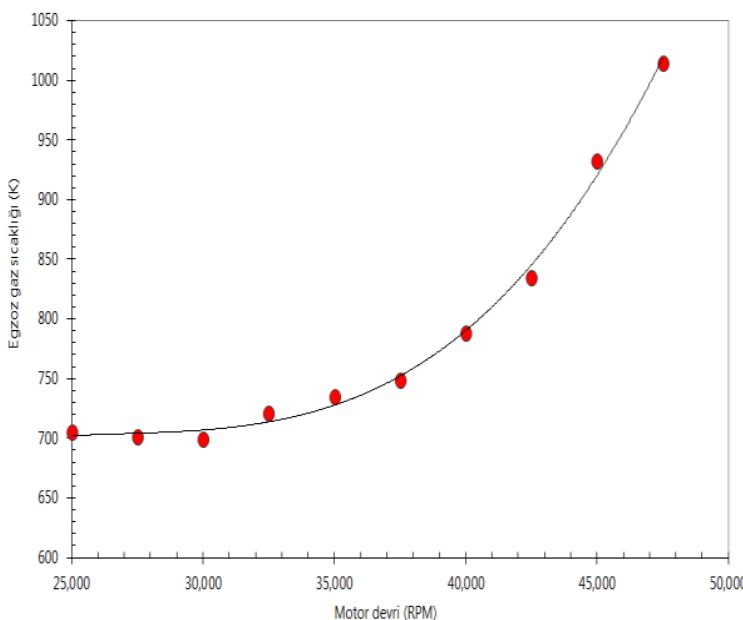

Şekil 18. Deneysel motorun itki kuvvetiyle motor devriyle egzoz gaz sıcaklığının değişimi

Şekil 18'de ise motor devriyle egzoz gaz sıcaklığı arasındaki değişim görülmektedir. Düşük motor devirlerinde egzoz sıcaklığ $700-730^{\circ} \mathrm{C}$ aralığında iken özellikle 40.000 devirden sonra egzoz sıcaklığının önemli miktarda arttığ 1 görülmektedir.

$\tau$, itki kuvveti; FF, yakıt debisi; RPM, motor devri, EGT, egzoz gaz sıcaklığı, SFC, özgül yakıt sarfiyatı, R güvenirlik katsayısı olmak üzere; füzelerde kullanılabilecek bir turbojet motor için buradaki deneysel çalışmada elde edilen önemli diğer matematiksel bağıntılar aşağıdaki gibi bulunmuştur:

i. $\quad \mathrm{SFC}=0.0005 \tau^{6}-0.0192 \tau^{5}+0.2728 \tau^{4}-1.8728 \tau^{3}+6.7346 \tau^{2}-16.877 \tau+69.74,\left(\mathrm{R}^{2}=0.9979\right)$

ii. $\quad \mathrm{FF}=0.0028 \tau^{6}-0.1017 \tau^{5}+1.4437 \tau^{4}-9.7144 \tau^{3}+31.77 \tau^{2}-37.289 \tau+40.938,\left(\mathrm{R}^{2}=0.9989\right)$

iii. $\quad \mathrm{EGT}=-0.0001 \mathrm{FF}^{3}+0.0494 \mathrm{FF}^{2}-2.9047 \mathrm{FF}+747.97,\left(\mathrm{R}^{2}=0.998\right)$

iv. $\quad \mathrm{SFC}=7 \mathrm{E}-08 \mathrm{RPM} \mathrm{M}^{2}-0.0061 \mathrm{RPM}+167.8,\left(\mathrm{R}^{2}=0.9968\right)$

v. $\quad \tau=1 \mathrm{E}-06 . \mathrm{RPM}^{2}-0.0577 \mathrm{RPM}+654.44,\left(\mathrm{R}^{2}=0.9986\right)$

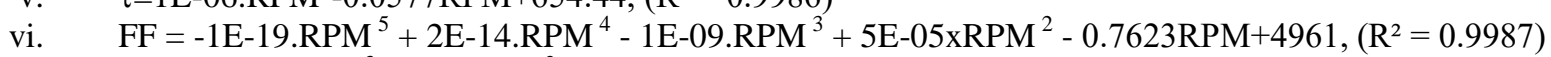

vii. $\quad \mathrm{EGT}=3 \mathrm{E}-11 \mathrm{RPM}^{3}-3 \mathrm{E}-06 \mathrm{RPM}^{2}+0.0754 \mathrm{RPM}+14.478,\left(\mathrm{R}^{2}=0.9955\right)$

\section{SONUÇLAR}

Bu çalışmada, füzelerde kullanılabilecek küçük ölçekli bir turbojet motorun deneysel verileri yardımıyla motor devrine bağlı olarak motorun performans parametreleri hesaplanmış ve motorun karakteristiği ortaya çıkartılmıştır. Çalışmadan elde edilen temel sonuçlar şu şekildedir:

a) Motorun maksimum devrinde elde edilen $1260 \mathrm{~N}$ itki kuvveti için gerekli olan yakıt debisi $149.27 \mathrm{~kg} / \mathrm{h}$ değerinde olması gerektiği ölçülmüştür.

b) Maksimum motor devri ve maksimum thrust değerinde egzoz gaz sıcaklığının $1015^{0} \mathrm{C}$ değerine çıktığ görülmüştür.

c) Motor devri arttıkça itki kuvveti artmakta, daha verimli yanma sayesinde motor veriminde yükselme olduğu, motorun özgül yakıt sarfiyatının ise azaldığı görülmektedir.

d) Motor devri ile itki kuvveti arasında doğrusala çok yakın bir ilişki mevcuttur.

e) Düşük motor devirlerinde egzoz sıcaklığ $700^{\circ} \mathrm{C}-730^{\circ} \mathrm{C}$ aralığında iken özellikle 40.000 devirden sonra egzoz sıcaklığının önemli miktarda arttığı görülmektedir.

f) İtki kuvveti, yakıt debisi, motor şaftı devri, egzoz gaz sıcaklığı, özgül yakıt sarfiyatı, R güvenirlik katsayısı olmak üzere; füzelerde kullanılabilecek bir turbojet motor için buradaki deneysel çalışmada elde edilen önemli matematiksel eşitlikler elde edilmiştir. 
Çalışmanın sonraki aşamasında, turbojet motorunun deneysel sonuçlarına dayanarak ekserji analizi yapılması planlanmaktadır.

\section{KAYNAKLAR}

[1] DİNÇ, A., "Optimization of a Turboprop UAV for Maximum Loiter and Specific Power Using Genetic Algorithm", International Journal of Turbo\&Jet Engine, DOI 10.1515/tjj-2015-0030, 2015.

[2] FAA. Federal Aviation Administration, Aviation Safety Unmanned Aircraft Program Office (UAPO), Interim Operational Approval Guidance. Unmanned Aircraft Systems Operations in the U. S. National Airspace System, 2008.

[3] U.S. Department of Defense. Office of the Secretary of Defense 2007-2032 Unmanned Systems Roadmap, 2007.

[4] GUHA, A., "Optimization of Aero Gas Turbine Engines”, The Aeronautical Journal, 105, 1049, 345-358, 2001.

[5] GUHA, A., "Performance and Optimization of Gas Turbine Engine with Real Gas Effects", Proceedings Institution of Mechanical Engineers, 215, 4, 507-512, 2001.

[6] BAKLACIOĞLU, T., TURAN, O. and AYDIN, H., “ Dynamic Modeling of Exergy Efficiency of Turboprop Engine Components Using Hybrid Genetic Algorithm-Artificial Neural Networks”, Energy, 86, 709-721, 2015.

[7] TURAN, O., "Effect of Reference Altitudes for a Turbofan Engine with the Aid of Specific-Exergy Based Method", International Journal of Exergy, 11, 252-270, 2012.

[8] TURAN, O.,"An Exergy Way to Quantify Sustainability Metrics for a High Bypass Turbofan Engine”, Energy, 86, 722-736, 2015.

[9] TURAN, O., "Exergetic Effects of Some Design Parameters on the Small Turbojet Engine for Unmanned Air Vehicle Applications, Energy, 46, 51-61, 2012.

[10] TURAN, O., AYDIN, H., “ Exergetic and Exergo-Economic Analyses of an Aero-Derivative Gas Turbine Engine”, Energy, 74, 638-650, 2014.

[11] BÜLBÜL, A., "TRS-18 Test Bremzesi”, Anadolu Üniversitesi Sivil Havacılık Yüksekokulu Bitirme Tezi, 2010.

[12] http://www.microturbo.fr/article.php3?id_article=174\&lang=en (erişim tarihi: 22.01.2010)

[13] MATTINGLY, D., J., "Elements of Gas Turbine Propulsion", McGraw-Hill, International Editions, Singapore, 1996.

[14] OATES, C., G., "Aerothermodynamics of Gas Turbine and Rocket Propulsion”, Fourth Printing, AIAA Education Series, ABD., 1998.

[15] TURAN, Ö., “ Gaz Türbinli Motorlarda Performans Analiz ve Değerlendirme Programları”, Yüksek Lisans Tezi, Anadolu Üniversitesi, Fen Bilimleri Enstitüsü, Eskişehir, 2000.

[16] DOPELHEUR, A., “Aircraft Emission Parameter Modelling”, Air and Space Europe, 2, 34-37, 2000.

[17] TRS18a Turbojet Motorunun Eğitim Manüeli, Microturbo Company, 1993. 